\title{
Strategic Orientation and External Environment on Organizational Commitment
}

\author{
Basim Abbas Kraidy JASSMY1 \\ Cristian-Silviu BANACU2 \\ Zaki Muhammad Abbas BHAYA ${ }^{3}$
}

\begin{abstract}
Aims of this study is to investigate the impact of the dimensions of strategic orientation (i.e. customer orientation, competitor orientation and interfunctional coordination) and the aspects of external environment (i.e., market turbulence and competitive intensity) on organizational commitment in the agricultural bank in AL-Qadissya governorate in Iraq.

Materials and methods -To achieve the aim the data collected through questionnaire survey applied to 54 employees in various departments of the bank. The data analysis performed by using SPSS (version 20) and $R$ program. Results -Statistical findings revealed there is a significant relationship between competitor orientation, interfunctional coordination, competitive intensity and organizational commitment. There is no significant relationship between market turbulence, customer orientation and organizational commitment. Conclusion - These findings introduce useful views and conclusion for the management to take into account for developing organizational commitment among their employees. According to the study, all the dimensions of strategic orientation and influences of external environment to increase organizational commitment could enhance findings. Besides, findings have significant implications for a bank's strategies to develop organizational commitment and to uncover the influences of market turbulence and competitive intensity. Managers should take interest in the role of strategic orientation besides external environment to improve organizational commitment. Managers should also develop a robust culture which reflects organizational commitment in order to ensure the survival of the bank and its growth when facing competitors and overcoming any challenges.
\end{abstract}

KEYWORDS: competitive intensity, strategic orientation, market turbulence, organizational commitment, strategic orientation

JEL CLASSIFICATION: $G 32, C 15, M 15, I T$

\section{INTRODUCTION}

Previous strategic orientation literature has asserted the importance of strategic orientation for organizational performance (Kohli \& Jaworski, 1990; Narver \& Slater 1990). It has been confirm that a long-term sustainability of the organization's advantage can be achieve and maintained by responding to customer needs and wants (Lai et al., 2009). Furthermore, some scholars like Ozsahin et al. (2013) demonstrated that strategic orientation represents a source of competitive advantage and that it brings success to the organization. Idar et al. (2012) refers to strategic orientation as the organization's culture that most effectively and efficiently

\footnotetext{
${ }^{1}$ The Bucharest University of Economic Studies, Romania, basimabbas55@ yahhoo.com, corresponding author

2 The Bucharest University of Economic Studies, Romania.Cristian.banacu@gmail.com

${ }^{3}$ The Bucharest University of Economic, Romania, Zakimohammad2008@ yahoo.com
} 
employs the suitable behaviours for producing superior value for the customer, bringing performance to the organization and proving there is a significant relationship between strategic orientation and performance (Naidoo, 2010). Strategy is the first step taken by an organization as reaction to the business environment conditions (Slater \& Narver, 1994). Strategic orientation cannot influence directly on financial performance by ignoring information. Salyova et al. (2015) clarify the importance of strategic orientation and its effect on profitability by being better than the competitors, resulting from implementing strategic orientation in the market. The results demonstrate that strategic orientation is significant to organizational performance. Some scholars conclude that strategic orientation can influence directly or indirectly the organization performance (Suliyanto \& Rahab, 2012).

Felgueira and Rodrigues (2015) reported that higher degree of strategic orientation is improving the organizational performance. Wei et al. (2014) proved that besides the direct relationship between strategic orientation and performance, proactive and responsive strategic orientation is essential for organizational norms and beliefs, which effect the organizational performance.

Organizations should generate and disseminate market intelligence on facing customer needs and wants to improve their success compared with competitors (Kirca, 2011). Strategic orientation concepts are common behaviours in the organizations or some procedures that create superior customer value (Suliyanto \& Rahab, 2012). Market conditions are faced by any organization and to respond to these conditions, an organization must develop something new or different from its competitors (Jaworski \& Kohli, 1993).

Although strategic orientations in organizations are identified in different ways, including the use of multiple terms commensurate with the direction, direction and desires of the department, it represents a formula of strategy in improving the organization's performance Mariadoss et al. (2016).

The strategic orientation is direct to processes that represent decision-making in the process of activities and innovation of the working organization Zhang et al. (2016). Likewise Newman et al. (2016). The main objective of the organization's approach to the market is mainly to provide high value to customers through the ideas gained by the organization by analyzing competitors and customers and balancing them.

Some scholars differentiate between strategic orientation and marketing orientation, while others consider them the same. The authors prefer using strategic orientation because it has been widely used in scientific research (Salyova et al., 2015). For organizations, the environment has become more sophisticated than ever before. In this environment, organizations should follow the rapid changes in the needs, wants of the customer, and should be closer to the customer and market to overcome competitors and to gain competitive advantage (Chang, 2014).

Our research attempts to contribute to the external environment and strategic orientation, as well as to the role of strategic orientation in improving organizational commitment in an effort to fill in an important gap in previous research that details the effects of strategic orientation on organizational commitment.

The majority of the literature was publish in developed countries and only partly, the results of those studies can be apply to the Middle East region due to differences in strategic 
orientation. In advanced countries, the attitude towards strategic orientation is more positive than in emerging countries. However, literature provides some evidence on the effect of strategic orientation on organizational commitment in the Middle East region. The literature review indicates some studies in different countries, while there is no previous study on Iraqi banks. To fill this gap, we investigated the effect of strategic orientation on organizational commitment in the agricultural bank located in Al-Qadissya governorate in Iraq. The mechanism through which strategic orientation affects the organizational commitment has not received adequate attention. Moreover, this study also emphasises the importance of strategic orientation in the organizational commitment with external environment (market turbulence and competitive intensity), addressing this gap as well.

\section{REVIEW OF THE SCIENTIFIC LITERATURE}

\subsection{Behavioural perspective versus cultural perspective for strategic orientation}

Kohli and Jaworski (1990) and Narver and Slater (1990) developed two major perspectives the one first is called behavioural perspective and the second one is called cultural perspective.

\subsubsection{Behavioural perspective}

Kohli and Jaworski (1990) introduced a form for strategic orientation definition called behavioural perspective that concerns intelligence related with current and latent needs of customer; it includes three types of activities:

a) Organization-wide generation of strategic orientation concerning current and latent needs of customer.

b) Dissemination of the information between the departments in the entire organization .

c) Responsiveness of the whole organization to various information brought from intelligence. Moreover, the study describes how strategic orientation is relate to generation of information, dissemination and responsiveness to market intelligence and emphasis of market information (Kirca, 2011; Kohli \& Jaworski, 1990; Lai et al., 2009). Ozsahin et al. (2013) have the same approach but added the focus on current as well as future needs of the customer, which defines the strategic orientation as obtaining information whether the needs are current or latent needs (Chad, 2013).

Many scholars have used this perspective and tried to measure strategic orientation behaviours in their studies (Zhang, 2008). Therefore, the behavioural perspective is define as a response to competitive operational dynamics that surround the organization (Naidoo, 2010).

\subsubsection{Cultural perspective}

Narver and Slater (1990) discussed that organizational culture has three components: customer orientation, competitor orientation and interfunctional coordination. These components implemented by the decision criteria have a long-term perspective and aim to have a positive impact on profitability. Therefore, the cultural perspective concentrates on organizational norms and values that will create best behaviours depending on the capacity to react of the targeted market according to the company's knowledge of customers and competitors.

Kirca (2011) and Idar et al. (2012) relate to the perspective that the primary culture of the organization is to create essential value for customers, to enforce the customer position as the highest priority for its work. Therefore, part of the organizational culture is to create a group 
of behaviours or activities called 'strategic orientation' (Hurley and Hult 1998), considering the strategic orientation as the component of cultural organization that generates superior value for customer by building effective and efficient behaviours. This may generate optimal performance for the organization (Lai et al. 2009).

The study of Ozsahin et al. (2013) describes strategic orientation as culture that represents excellent performance by its organizational commitment in order to bring superior value for present and future customers. The three components include customer orientation, competitor orientation and interfunctional coordination. The organizations focus on two decisions standards: long-range focus and profitability results (Chad 2013, Felgueira and Rodrigues 2015). Therefore, some scholars attempted to assess which perspectives are useful for building the company. According to Narver and Slater (1990), the most important is forecasting the power for the work (Zhang 2008). The authors also recommend strategic orientation (Narver and Slater 1990) because it focuses on organizational culture, which builds the organizational commitment as a view of organizational capability (Ozsahin et al. 2013).

\section{Customer orientation}

Auh and Menguc (2007) discussed the customer orientation as enforcement of the ability to enhance performance, which appears more as control among organizations. This orientation has been accepted as customer orientation and through the definition in which the organization strives to understand the customer needs and wants (Dev et al., 2009); customer orientation has significant influence on organizational performance.

Brockman et al. (2012) debated that customer orientation boosts the performance and has impact in risk taking through innovation and creating opportunity. Customer orientation refers to focusing on the needs of the target market, which creates excellent customer value with strong customer orientation. Moreover, Theoharakis and Hooley (2008) refer to the combination between customer orientation and organizational innovation, which in their opinion is very difficult to obtain, or it takes more time to achieve. From the competitors, organizations are facing limits related to imitation, which may isolate the organization.

Thakor and Joshi (2005) found that customer orientation has a positive impact on the organization and it can enhanced by identifying and producing goods and services to match customer requirements and thus increasing customer satisfaction. Ndubisi (2011) indicates that customer orientation is positively significant for customer satisfaction. Some scholars discussed the customer-oriented approach for qualifying, determination and quantifying the needs and wants of the customer as part of product or service development procedures (Naidoo, 2010).

Despite the fact that customer orientation is use as equivalent term for strategic orientation or as a basic part of wide definitions of strategic orientation, it is describe as the relationship between the customer and the organization. Strategic orientation concerns the organization's activities (Rapp et al., 2012). Customer orientation is consider as the ability of salespeople to introduce assistance of their customers in the form of quality of the relationship between the customer and the salesperson. However, Herhausen (2011) mentions that organizations must endeavour to recognize and incorporate the most important drivers to maximize their capacity to investigate latent and uncovered customer requirements. The organization should identify the best positions and follow detailed recommendations for technological driven innovators and constraints facing these resources. Bhattacharyya and Jha (2014) focused on 
organizations that are close to their markets. Such organizations that respond to the needs and preferences of their customers would demonstrate customer orientation and would be in a better position to recognize their customer according to their knowledge of the shifting customer requirements.

Suliyanto and Rahab (2012) mention that organizations should continuously boost strategic orientation by collecting customer information. Moreover, Kirca (2011) concluded that connecting the customer to a mechanism (i.e., customer satisfaction and retention) could facilitate the transfer from strategic orientation into improved organizational performance. Ozsahin et al. (2013) demonstrates that the customer should have high priority but without excluding the other stakeholders in order to achieve high profit. This done by following the needs and wants of customer in the present time and the future because the customer represents the heart of organization. Altinay (2010) advocates for a continuous proactive disposition to meet customer requirements. Furthermore, Singh and Koshy (2011) suggested creating value for customer by enforcing the customer relationship and that is achieve by sales oriented people and focusing on short term goals. Zhou and Li (2007) define the customer orientation as adequate understanding of the targeted customer.

Pousa and Mathieu (2014) found that to achieve performance, organizations need to train their employees to develop their customer-orientated attitudes and reduce profit-oriented behaviour. The authors discussed the differences between customer orientation and sales orientation by clarifying these items. Customer orientation refers to behaviours of individuals oriented to make better customer decisions that will enhance their satisfaction and thus creating customer trust which leads to customer retention and finally to achieving performance. Sales orientation indicates the capacity of a salesperson to utilize selling techniques and tactics to persuade the customer to buy the product or service. Rapp et al. (2010) found that customer orientation is in a positive relationship with sales capability and this research brought significant changes in the external environment, considered as a moderate variable in this relation.

Jones et al. (2003) concluded that strategic orientation is positively influence by customer orientation through organizational commitment. Thurau (2004) reported that the key driver for customer satisfaction begins with individual level of customer orientation, and that is clearly stronger than organizational commitment or retention. In order to maintain this relationship with their customers, organizations should follow their customer commitment by customer satisfaction and retention (Ozsahin et al., 2013)

\section{Competitor orientation}

Zhou and $\mathrm{Li}$ (2007) define competitor orientation as focusing on identifying rivals' strengths and weaknesses and following their actions. Competitor orientation for organizations is their focus on monitoring the actions of their competitors. Dev et al. (2009) revealed that there was no significant relationship between competitor orientation and organizational performance.

The study of Suliyanto and Rahab (2012) concluded that organizations should increase strategic orientation by gathering information about competitors whether recent or latent. Ozsahin et al. (2013) discussed that competitor orientation enables organizations to develop a wider vision of strategies for gaining competitive advantage. Moreover, observing all competitors whether current or potential enables companies to understand their strengths and weaknesses. Naidoo (2010) discussed the relationship between competitor orientation and the organization's ability to determine, sustain and increase its strengths and to reduce the 
weaknesses compared with competitors. In the work of Altinay (2010) is recommend for organizations to understand current and potential competitors and to collect more information about strengths and weakness, both on short terms as well as on long term.

Debruyne et al. (2010) when analysing competitor orientation asserted that it is connect to all functions. The approach of managers is to overcome their competitors by any means, which may lead to increased revenue, but on the long run, this approach may become incompatible with other aspects. Bendle and Vandenbosch (2014) observed that managers were encouraged, revenue increased but also initiative can suffer. Zhou and Li (2007) indicated that customer and competitor orientation function differently and their significance for the performance of companies differs across various market situations. Jiang and Kortmann (2014) analyse the ability of organizations to collect information and knowledge faster than rivals do. This ability develops the knowledge resources that are difficult to imitate by competitors to bring valuable asset in mobile markets where imitation is widely employed. Moreover, Powpaka (2006) discussed that the two orientations (customer and competitor) are design to include all activities that are perform in order to gather information about customers and competitors in the market and to spread this information through various management functions.

Foreman et al. (2014) investigated how to measure strategic orientation on customer and competitor orientation with removing interfunctional coordination, because this construct reflects coordination between all the levels of an organization. On the other hand, it is difficult to measure this construct by using objective standards. The authors support this viewpoint because it is very important to acknowledge the role of this construct among departments. This approach is rare, and we can exclude any bias by using statically scientific methods. In addition, the authors used the same dimensions as Narver and Slater (1990).

\section{Interfunctional coordination}

Although Rapp, et al. (2012) refer of the interfunctional dimension which consists of coordinating all the resources across functions to improve customer value and achieve superior levels, the organization must put the suitable technological infrastructure in place for the external sales force. Suliyanto and Rahab (2012) consider that in order to improve strategic orientation, an organization should strive to continuously coordinate all functions. Ozsahin et al. (2013) refer to this component as a competitive advantage and it can be incorporate in any department of an organization by understanding the role of every employee. Zhou and Li (2007) consider that the use of all resources and customer-related functions should be coordinated through the entire organization. Dev et al. (2009) defined organizational culture as the concept that directs all employees in all departments of the business towards understanding the firm's market; the authors found that there is no significant relationship between interfunctional coordination and organizational performance. Furthermore, Salyova et al. (2015) defined interfunctional coordination as management and utilization of resources for creating best value for customer.

Naidoo (2010) discussed that interfunctional coordination was relate with the organization's capacity to unify all efforts within the organization to implementation and coordinate among different functions. Moreover, Altinay (2010) refers to sharing information among departments in the organization and implementing new strategies to develop the activity and put new plans into action to overcome competitors. 
Powpaka (2006) reported the interfunctional coordination depends on customer and competitor orientation information and it involves the entire organization to coordinate the efforts for creating best value for customer. According to the authors, the there is no relation between competitor orientation and organizational commitment.

\subsection{Market turbulence}

Rapp et al. (2010) found that the external environment of the organization, which is measure by the dynamism of the environmental structure, has significant impact on the performance, which is important to take into consideration. Efforts have been dedicate to investigate the impact of environment conditions on strategic orientation (Kirca, 2011).

Many scholars examined the relationship between strategic orientation and organizational performance, which is different according to the industry characteristics and type (Kirca, 2011). Lai et al. (2009) argued that the environmental variables could not disturb the processes, but could bring opportunities to the organization.

Appiah-Adu and Singh (1998) as well as Jaworski and Kohli (1993) debated that the levels of environmental turbulence is essential for dealing with customers. In the case of a high market turbulence, a positive approach is to adapt according to the organization's readiness to reduce uncertainty. On the other hand, if the organization is facing a stable market turbulence when the customer requirements are not rapidly changing during short periods, the organization has to make little adaptations and instead needs to focus on customer orientation.

\section{Competitive intensity}

Saboo and Grewal (2013) indicated that competitive intensity is define as the mixture of behaviours, resources and capacities of competitors. The competitive intensity increases due to competitive dynamism, so the value of competitor orientation is very important in monitoring their activities; thus, competitor orientation will grow with higher competitive intensity. Foreman et al. (2014) stated that the role of competitive intensity is a moderate variable between strategic orientation and performance. In highly competitive environment, the organization is required to concentrate more effort in the identification of competitors; therefore, organizations focus on their competitors in order to avoid customer loss. This approach is different from the approach used in stable environmental conditions.

Appiah-Adu and Singh (1998) indicated that for organizations facing a highly competitive environment, customers have many alternatives to satisfy their preferences and needs. In this case, the organization needs to be more sensitive and offer a more adequate response to customer needs in rapidly changing environment. Therefore, if an organization is not customer orientated, it may be facing the risk of customer loss due to high competition.

The results from previous studies concerning the environmental factors were inconclusive (Kirca 2011). A review of previous studies that investigated the relationship between strategic orientation and environmental factors (i.e. market turbulence, competitive intensity) was developed and investigated in various studies such as the study Jaworski and Kohli (1993).

\subsection{Organizational commitment}

Atak and Erturgut (2010) describe the organizational commitment as a function that aims to reduce the absenteeism and turnover while avoiding any disruption in the activity. Therefore, it is important to boost the quality and quantity of the actions and decisions that reduce absenteeism and turnover and that increase behaviours essential for the success of the organization's processes. Ozsahin et al. (2013) defined organizational commitment as the behavioural vision or perspective identified as participation, which is describe as the desire to 
remain in the organization while the organizations employ important efforts in creating a positive environment for their employees. Organizational commitment has been the theme of many theoretical and experiential studies in the field of organizational behaviour (Dhurup et al., 2016). Lai et al. (2009) indicated that strategic orientation is focus on customer satisfaction and organizational commitment. Some researchers like Ozsahin et al. (2013) discussed that the strong desire to stay with the company is specific for organizations that are ready to allocate important efforts for employees' satisfaction; it also appears if the values and beliefs of the company are the same as those of the employee. Hanaysha (2016a) indicated that the connection between individuals has a significant positive impact on organizational commitment and reported that organizational learning culture can be consider as one of the main variables for commitment.

Lai et al. (2009) stated that there is a positive relationship between high commitment, strategic orientation and performance. Ozsahin et al. (2013) discussed that increasing organizational commitment is at the top of actions taken for reaching performance in an organization. Organizational commitment occurs when organizations focus on recruiting employees and retaining valuable employees. Hanaysha (2016b) indicated that individuals' attitude has positive effect on organizational commitment; organizational commitment is the level of enthusiasm of the individuals on continuing working for the organization. Powpaka (2006) discussed that the strategic orientation minimizes the employees' stress like confusion and conflicting by maximizing job satisfaction and organizational commitment. Felgueira and Rodrigues (2015) demonstrated that if individuals feel that they bring positive contribution to the company, their attitude is transfer to commitment to the organization and brings satisfaction, in the end enabling the organization to respond to customer requirements. Amdan et al. (2016) conclude that organizational commitment is essential to maintain individuals' productivity and efficiency at high levels. Turnover can be a cause for understaffing which can lead to lower profitability, in case the organization is not focus on organizational commitment. Salahudin et al. (2016) show that organizations with high organizational commitment have a solid human capital and a competitive advantage compared with other companies active in the same field. Individuals are ready to work to enhance their organization's success, which indicates a match between values and motivation. Creating loyalty as indicator of high organizational commitment represents one of the main objectives of organizations.

Atak and Erturgut (2010) indicated that the dimensions of organizational commitment are influenced by various conditions. Some researchers have challenged the role of organizational commitment in the organizational goals. Allen and Meyer (1990) presented three components of organizational commitment to discuss this concept: affective commitment, normative commitment and continuance commitment.

Affective commitment results from emotions of the individuals coming from positive experiences. A strong affective commitment motivates employees to remain in the organization because their expectations are met. Salahudin et al. (2016) include three aspects: the emotional response to the organization, identification of the role of these emotions and identification of the organizational mechanisms (Dhurup et al. 2016). Adman et al. (2016) refers to the emotional connection to the organization such as the feeling of belonging.

Normative commitment occurs when the employees stay with a company because of social and organizational cultures (Dhurup et al. 2016, Salahudin et al. 2016). Adman et al. (2016) refer to these feelings as feelings of ethical obligation. 
Continuance commitment represents the concerns with leaving an organization (Dhurup et al. 2016). It is connect to turnover and depends on financial changes between the individuals and organization (Salahudin et al., 2016). Adman et al. (2016) distinguished a more reasonable analysis of the assets against costs of leaving the organization. Dhurup et al. (2016) described it as a combination of positive and negative aspects of working in an organization.

In this study, the authors examine the strategic orientation as part of the organizational culture and organizational commitment. Organizations should prevent dissatisfied employees, which create conflict. Workplace conflict can prevent the organization to reach its goals, which are represent by customer satisfaction.

\section{RESEARCH METHODOLOGY}

The purpose of this study is to investigate the relationship between strategic orientation and organizational commitment. Besides the relationship between external environment and organizational commitment based on previous studies hypotheses, the following basic hypothesis is proposed:

H: Strategic orientation (customer orientation, competitor orientation and interfunctional coordination) and external environment (market turbulence and competitive intensity) have influence on organizational commitment.

\subsection{The scale}

For measuring the strategic orientation according to Narver and Slater (1990), the Likert scale use to capture the behaviour of respondents in various functions of the organization (Salyova et al., 2015). The population for this study was the agricultural bank in Al-Qadissya governorate in Iraq. A questionnaire survey was distribute to the managers of the agricultural bank. 75 questionnaire forms were distributed and 60 returned, out of which 54 were valid and useable. These questionnaire forms were suitable to apply SPSS V 20.0 and R program. The research model developed within the context of this study is present in figure no. 1.

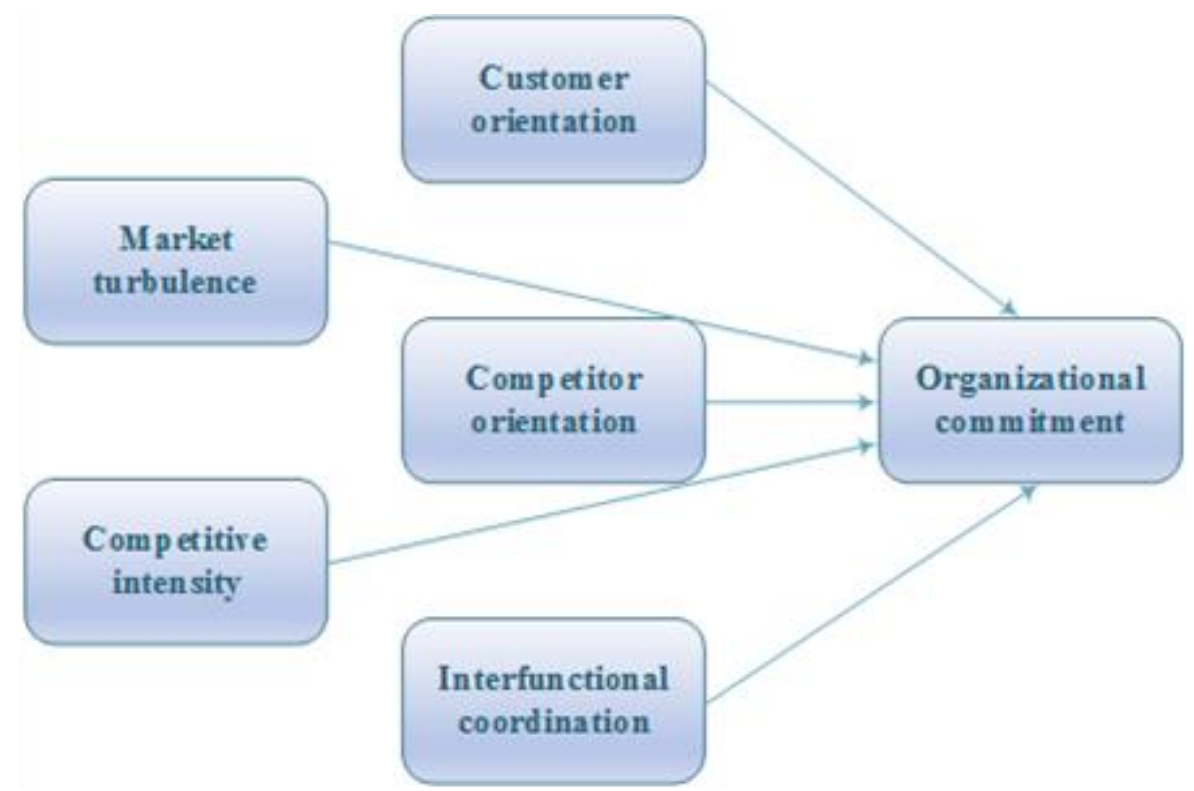

Figure 1. Conceptual framework

Source:prepared by atuhors 
Figure 1 presents the hypothesis measurement model used in this study. The data were obtain from developing a questionnaire with the dimensions of the external environment (market turbulence and competitive intensity) from the studies of Auh and Menguc (2007) and Kirca (2011); strategic orientation from the work of Naidoo (2010); organizational commitment from Ozsahin et al. (2013). A five-point liker scale was used ranging from 1 (strongly disagree) to 5 (strongly agree). The gathered data from questionnaires were analysed through SPSS 20.0 and $\mathrm{R}$-program. The items of the questionnaire were divide into 3 items for market turbulence, 5 items for competitive intensity, 5 items for customer orientation, 4 items for competitor orientation, 3 items for interfunctional coordination and 7 items for organizational commitment.

Table 1 shows all the items from each of the dimensions and Cronbach's Alpha for each one of them.

Table 1. Results of reliability for Cronbach's Alpha

\begin{tabular}{|c|c|c|}
\hline Construct & No. of items & Cronbach's alpha \\
\hline Market turbulence (mark) & 3 & .720 \\
\hline Competitive intensity (compin) & 5 & .742 \\
\hline Customer orientation (cus) & 5 & .744 \\
\hline Competitor orientation (com) & 4 & .776 \\
\hline Interfunctional coordination (inter) & 3 & .731 \\
\hline Organizational commitment (org) & 7 & .755 \\
\hline
\end{tabular}

Source: prepared by authors

This paper developing based on previous studies, while some of the questions modified in order to be more relevant to the purpose of the study. For the reliability test was conducted an analysis to determine the internal consistency of the scale used in this study which is higher according to Hair et al. (2006). The Cronbach's Alpha values indicated for all factors are above 0.70 showing the reliability of the scale used in this survey. The reliability coefficient is acceptable in order to eliminate the factors with low reliability.

\subsection{Analysis}

Table 2. Correlation matrix between the variables

\begin{tabular}{|c|c|c|c|c|c|c|}
\hline Variable & Y: & X1: & X2: & X3: & X4: & X5: \\
\hline Variable & 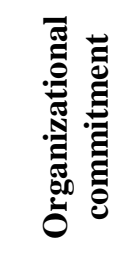 & 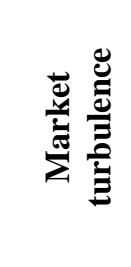 & & 总 & 泀 & 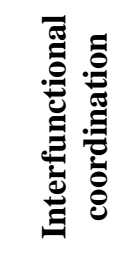 \\
\hline Y: Organizational commitment & 1 & $0.7622 \mathrm{a}$ & $0.7939 a$ & $0.8300 \mathrm{a}$ & $0.6487 \mathrm{a}$ & $0.6952 \mathrm{a}$ \\
\hline X1: Market turbulence & $0.7622 \mathrm{a}$ & 1 & $0.7814 \mathrm{a}$ & $0.5604 \mathrm{a}$ & $0.6466 \mathrm{a}$ & $0.7456 a$ \\
\hline X2: Customer orientation & $0.7939 a$ & $0.7814 \mathrm{a}$ & 1 & $0.7213 \mathrm{a}$ & $0.5604 \mathrm{a}$ & $0.7746 a$ \\
\hline X3: Competitive intensity & $0.8300 \mathrm{a}$ & $0.5604 \mathrm{a}$ & $0.7213 \mathrm{a}$ & 1 & $0.5048 \mathrm{a}$ & $0.5917 \mathrm{a}$ \\
\hline X4: Competitor orientation & $0.6487 \mathrm{a}$ & $0.6466 \mathrm{a}$ & $0.5604 \mathrm{a}$ & $0.5048 \mathrm{a}$ & 1 & $0.7416 \mathrm{a}$ \\
\hline X5: Interfunctional coordination & $0.6952 \mathrm{a}$ & $0.7456 a$ & $0.7746 a$ & $0.5917 \mathrm{a}$ & $0.7416 \mathrm{a}$ & 1 \\
\hline
\end{tabular}

${ }^{a}$ correlation is significant at the 0.01 level.

Source: prepared by authors.

From Table 2, the variable (organizational commitment) has significant and positive correlation relationship with the variables market turbulence and customer orientation. Competitive intensity, competitor orientation and interfunctional coordination have values of $\mathrm{r}=0.762$, 0.793, 0.830, 0.648, 0.695, respectively. All these correlations are significant at 0.01 level. 
Furthermore, market turbulence has significant and positive correlation with the variables customer orientation, competitive intensity, competitor orientation and interfunctional coordination, with values of $r=0.781,0.560,0.646,0.745$, respectively. All these correlations are significant at 0.01 level. The same table shows that the variable (customer orientation) has significant and positive correlation relationship with the variables competitive intensity, competitor orientation and interfunctional coordination, with the values of $r=0.721,0.560$, 0.774 , respectively. All these correlations are significant at 0.01 level. Moreover, in the same table the variable competitive intensity has significant positive correlation with the variables competitor orientation and interfunctional coordination, with (r) values as follows: $r=0.504$, 0.591. All these correlations are significant at 0.01 level. Finally, in the same table, the variable competitor orientation has significant positive correlation with interfunctional coordination $(\mathrm{r}=$ 0.741). The summary of these relationships is show in Figure 2.



Figure 2. The spread of relationship between the variables

Source:prepared by atuhors

Figure 2 presents the spread of the values of variables shows that there are positive and significant relationships between variables. From the spread of the values of variables, there are positive and significant relationships between these variables. The amount of these relationships between the variables is show in Figure 3. 




Figure 3. The amount of correlation relationships between the variables Source:prepared by atuhors

Figure no. 3 presents the amount of correlations between the variables. In this paper, quantile regression is use in order to provide the complete relationship between the dependent variable and independent variable, through building one more quantile regression line under different quantile levels. The quantile regression model is more robust compared with the classical regression model. In this paper, four quantile levels $(0.20,0.40,0.60$, and 0.80$)$ are use (based on the authors' opinion).

Table 3. Coefficient estimation for quantile regression models via four quantile levels

\begin{tabular}{|c|c|c|c|c|}
\hline \multirow[t]{2}{*}{ Coefficients } & \multicolumn{4}{|c|}{ quantile level } \\
\hline & 0.20 & 0.40 & 0.60 & 0.80 \\
\hline Intercept & $1.6207 \mathrm{a}$ & 2.7881 & 3.30892 & 3.4922 \\
\hline X1: Market turbulence & 1.3950 & 0.3826 & -0.13093 & -0.0188 \\
\hline X2: Competitive intensity & $-0.0897 \mathrm{~b}$ & $-0.1526 \mathrm{~b}$ & 0.04684 & -0.0747 \\
\hline X3: Customer orientation & 0.0820 & 0.1066 & 0.24595 & 0.2480 \\
\hline X4: Competitor orientation & $0.2403 \mathrm{a}$ & $0.2762 b^{*}$ & $0.13704 \mathrm{~b}$ & 0.1116 \\
\hline X5: Inter functional coordination & $0.0815 \mathrm{a}$ & $0.1031 \mathrm{~b}$ & -0.00269 & 0.0124 \\
\hline The pseudo- $\mathrm{R}$ squared & 0.7224185 & 0.5675732 & 0.334364 & 0.056272 \\
\hline
\end{tabular}

From table no. 3, the optimal quantile regression model in representation of the data under study is at quantile level (0.2), as a result from the pseudo- $\mathrm{R}$ squared. The quantile regression model at quantile level (0.4) also has strength in explanation of the data under study. The quantile regression models under two quantile levels $(0.60,0.80)$ have weakness in representation of the data under study. 
In this paper, the quantile regression models are focused at two quantile levels $(0.20,0.40)$, because the independent variables (market turbulence, competitive intensity, customer orientation, competitor orientation and interfunctional coordination) of these quantile regression models can explain $72.24 \%$ and $56.75 \%$ respectively from the variation in the dependent variable (organizational commitment).

\section{Quantile regression model at quantile level 0.20}

(a) Market turbulence variable

The estimated coefficient of market turbulence variable is 1.3950. This indicates that ceteris paribus, an increase in the market turbulence variable by one unit leads to an increase in the dependent variable (organizational commitment) by 1.3950 units, due to this variable being in a positive relationship with the dependent variable. It has insignificant effect on the organizational commitment variable.

(b) Competitive intensity variable

The estimated coefficient of the competitive intensity variable is -0.0897 . This indicates that ceteris paribus, an increase in the competitive intensity variable by one unit leads to a decrease in the dependent variable (organizational commitment) by 0.0897 units, due to this variable being in an inverse relationship with the dependent variable. It has significant effect on the organizational commitment variable.

\section{(c) Customer orientation variable}

The estimated coefficient of the customer orientation variable is 0.0820 . This indicates that ceteris paribus, an increase in the Customer orientation variable by one unit leads to an increase in the dependent variable (organizational commitment) by 0.0820 units, due to this variable being in a positive relationship with the dependent variable. It has insignificant effect on the organizational commitment variable.

(d) Competitor orientation variable

The estimated coefficient of the competitor orientation variable is 0.2403 . This indicates that ceteris paribus, an increase in the competitor orientation variable by one unit leads to an increase in the dependent variable (organizational commitment) by 0.2403 units, due to this variable being in a positive relationship with the dependent variable. It has significant effect on the organizational commitment variable.

(e) Interfunctional coordination variable

The estimated coefficient of the interfunctional coordination variable is 0.0815 . This indicates that ceteris paribus, an increase in the interfunctional coordination variable by one unit leads to an increase in the dependent variable (organizational commitment) by 0.0815 units, due to this variable being in a positive relationship with the dependent variable. It has significant effect on organizational commitment.

\section{Quantile regression model at quantile level 0.40}

(a) Market turbulence variable

The estimated coefficient of market turbulence variable is 0.3826 . This indicates that ceteris paribus, an increase in the market turbulence variable by one unit leads to an increase in the dependent variable (organizational commitment) by 0.3826 units, due to this variable being in a positive relationship with the dependent variable. It has insignificant effect on the organizational commitment variable. 
(b) Competitive intensity variable

The estimated coefficient of the competitive intensity variable is -0.1526 . This indicates that ceteris paribus, an increase in the competitive intensity variable by one unit leads to a decrease in the dependent variable (organizational commitment) by 0.1526 units, due to this variable being in an inverse relationship with the dependent variable. It has significant effect on the organizational commitment variable.

(c) Customer orientation variable

The estimated coefficient of the customer orientation variable is 0.1066 . This indicates that ceteris paribus, an increase in the Customer orientation variable by one unit leads to an increase in the dependent variable (organizational commitment) by 0.1066 units, due to this variable being in a positive relationship with the dependent variable. It has insignificant effect on the organizational commitment variable.

(d) Competitor orientation variable

The estimated coefficient of the competitor orientation variable is 0.2762 . This indicates that ceteris paribus, an increase in the competitor orientation variable by one unit leads to an increase in the dependent variable (organizational commitment) by 0.2762 units, due to this variable being in a positive relationship with the dependent variable. It has significant effect on the organizational commitment variable.

(e) Interfunctional coordination variable

The estimated coefficient of the interfunctional coordination variable is 0.1031 . This indicates that ceteris paribus, an increase in the interfunctional coordination variable by one unit leads to an increase in the dependent variable (organizational commitment) by 0.1031 units, due to this variable being in a positive relationship with the dependent variable. It has significant effect on organizational commitment.

The interpretation of quantile regression models at two quantile levels $(0.60,0.80)$ is not included due to the fact that these quantile regression models are not important in the interpretation of the data under study. This clear from the pseudo-R squared.

\section{RESULTS AND DISCUSSION}

This study provides an understanding on how strategic orientation and external environment can used to increase organizational commitment. Therefore, the statistical findings show that competitor orientation has a significant positive effect on organizational commitment and it is consistent with previous studies (Kirca, 2011; Rapp et al., 2010) and inconsistent with the study of Powpaka (2006). This study also confirmed that competitive intensity is one of the main factors that lead to organizational commitment and it is consistent with previous studies (Ozsahin et al., 2013; Hanaysha, 2016a; Hanaysha, 2016b).

The above statistical findings prove that there are significant strong relationships between competitive intensity, competitor orientation and interfunctional coordination on organizational commitment and this is consistent with previous studies (Powpaka, 2006; Rapp et al., 2010; Ndubisi, 2011; Dev et al., 2009). 


\section{CONCLUSION}

To achieve the objectives of this study the conceptual model was design on the constructs of strategic orientation, external environment and organizational commitment. Therefore, when employees are treat well, they handle their activities effectively in order to achieve the organizational goals and their level of commitment will increase as a result.

One of the debates in recent studies in strategic management is that strategic orientation improves organizational commitment. Therefore, some studies revealed that organizations can boost organizational commitment and that organizations that adapted strategic orientation to the external environment are more likely to improve organizational commitment than organizations that adopted strategic orientation without external environment. The effect of strategic orientation and external environment on organizational commitment is not clear. This study focuses on the importance of strategic orientation and organizational commitment and identifies the effects of external environment on organizational commitment. Findings revealed that strategic orientation and external environment are strongly correlated with organizational commitment.

These findings are expect to provide management and participants in the strategic management with useful feasible insights into the relationship between the model of strategic orientation and organizational commitment. Managers should take interest in the role of strategic orientation besides external environment to improve organizational commitment. Managers should also develop a robust culture which reflects organizational commitment in order to ensure the survival of the company and its growth when facing competitors and overcoming any challenges. Companies offering services may need to focus more on adaptation than those with core business on production, because the interaction with customer in service offering business is crucial. Additionally, a comfortable working environment is important to enable employees to focus on their working and to improve their activities, resulting in commitment for the organization. Employees feel motivated which leads to higher individual performance and thus, overall better performance of the company (in this case, of the bank).

Finally, only five variables were consider to investigate the effects on organizational commitment. Hence, future studies are suggest to test other variables, such as internal variables that include leadership charisma and organizational culture.

\section{LIMITATIONS}

Although this study may have expanded the scientific knowledge about strategic orientation, market turbulence, competitive intensity, organizational commitment within the baking industry in Iraq, a few limitations must be mention here. The data was collect from agricultural bank through self-reporting from the perspective of employees. Future studies could be extend to other banks in Iraq to obtain more comprehensive understanding of the relationship between strategic orientation and external environment on organizational commitment. This study tried to contribute to the knowledge base of existing literature on strategic management and organizational behaviour in the banking industry in Iraq.

This study focused on one selected bank, which is located in AL-Qadissya governorate in Iraq. The sample of this study may be limited for generalization to the whole population in the banking industry. This study finding are suitable and useful to measure the effects of strategic orientation and external environment in agricultural bank in Iraq. 
In our point view, in order to expand the sample to cover more banks in Iraq to generalize these results, future research may include internal and external environment to clarify the overall image of banks according to the entire environment that surrounds the banks. Another thing that must be mention here is if it is efficient to utilize the information to employees in all functions in the organization.

Moreover, the sample size is also relatively small and only focuses on agricultural bank, but not across Iraq. Therefore, future study needs to be carried out empirically to test further specific types of industry to attain better understanding.

For future researches, the selected sample based on a non-probability sampling method, which occurs to not representative the whole population. Moreover, the study does not contain the opinions of external population on the services of the bank.

Future studies may choose to investigate various types of commitment (affective, normative and continuance) in the banking industry.

\section{REFERENCES}

Allen, N. J., \& Meyer, J. P. (1990). The measurement and antecedents of affective, continuance and normative commitment to the organization. Journal of occupational and organizational psychology, 63(1), 1-18. https://doi.org/10.1111/j.20448325.1990.tb00506.x

Altinay, L. (2010). Market orientation of small ethnic minority-owned hospitality firms. International Journal of Hospitality Management, 29(1), 148-156. https://doi.org/10.1016/j.ijhm.2009.07.004

Amdan, S., Rahman, R. A., Shahid, S. A. M., Bakar, S. A., Khir, M. M., \& Demong, N. A. R. (2016). The role of extrinsic motivation on the relationship between office environment and organisational commitment. Procedia Economics and Finance, 37, 164-169. https://doi.org/10.1016/S2212-5671(16)30108-3

Appiah-Adu, K., \& Singh, S. (1998). Customer orientation and performance: a study of SMEs. Management Decision, 36(6), 385-394. https://doi.org/10.1108/002517498 10223592

Atak, M., \& Erturgut, R. (2010). An empirical analysis on the relation between learning organization and organizational commitment. Procedia-Social and Behavioral Sciences, 2(2), 3472-3476. https://doi.org/10.1016/j.sbspro.2010.03.537

Auh, S., \& Menguc, B. (2007). Performance implications of the direct and moderating effects of centralization and formalization on customer orientation. Industrial Marketing Management, 36(8), 1022-1034. https://doi.org/10.1016/j.indmarman.2006.02.010

Bendle, N., \& Vandenbosch, M. (2014). Competitor orientation and the evolution of business markets. Marketing Science, 33(6), 781-795. https://doi.org/10.1287/mksc.2014.0863

Bhattacharyya, S., \& Jha, S. (2014). Development of a model relating internal organizational variables with customer orientation in the context of the emerging economy of India. Asia-Pacific Journal of Business Administration, 6(1), 4-17. https://doi.org/10.1108/APJBA-04-2013-0034

Brockman, B. K., Jones, M. A., \& Becherer, R. C. (2012). Customer orientation and performance in small firms: Examining the moderating influence of risk-taking, innovativeness, and opportunity focus. Journal of Small Business Management, 50(3), 429-446. https://doi.org/10.1111/j.1540-627X.2012.00361.x

Chad, P. (2013). Extending the use of market orientation: Transforming a charity into a business. Australasian Marketing Journal (AMJ), 21(1), 10-16. https://doi.org/10.1016/ j.ausmj.2012.08.003 
Chang, W. J. (2014). Market orientation and business-to-business (B2B): a meta-analysis perspective. International Journal of Services Technology and Management, 20(1-3), 123-148. https://doi.org/10.1504/IJSTM.2014.063569

Debruyne, M., Frambach, R.T. \& Moenaert, R. (2010). Using the weapons, you have: The role of resources and competitor orientation as enablers and inhibitors of competitive reaction to new products. Journal of Product Innovation Management, 27(2), 161-178. https://doi.org/10.1111/j.1540-5885.2010.00708.x

Dev, C., Zhou, K. Z., Brown, J., \& Agarwal, S. (2009). Customer orientation or competitor orientation which marketing strategy has a higher payoff for hotel brands? Cornell Hospitality Quarterly, 50(1), 19-28. https://doi.org/10.1177/1938965508320575

Dhurup, M., Surujlal, J., \& Kabongo, D. M. (2016). Finding synergic relationships in teamwork, organizational commitment and job satisfaction: a case study of a construction organization in a developing country. Procedia Economics and Finance, 35, 485-492. https://doi.org/10.1016/S2212-5671(16)00060-5

Felgueira, T., \& Rodrigues, R. (2015). Market orientation of teachers and researchers in higher education institutions: a new approach. Procedia-Social and Behavioral Sciences, 174(12), 3017-3024. INTE (Proceedings of the International Conference on New Horizons in Education, 2014, 25-27 June 2014, Paris, France). https://doi.org/10.1016/j.sbspro.2015.01.1092

Foreman, J., Donthu, N., Henson, S., \& Poddar, A. (2014). The performance implications of planning, implementation, and evolution of firms' customer and competitor orientations. Journal of Marketing Theory and Practice, 22(4), 349-366.

Hair, J. F., Black, W. C., Babin, B. J., \& Anderson, R. E. (2006). Multivariate data analysis (sixth edition). New Jersey: Upper Saddle River.

Hanaysha, J. (2016a.) Testing the effects of employee engagement, work environment, and organizational learning on organizational commitment. Procedia-Social and Behavioral Sciences, 229, 289-297. https://doi.org/10.1016/j.sbspro.2016.07.139

Hanaysha, J. (2016b). Examining the effects of employee empowerment, teamwork, and employee training on organizational commitment. Procedia-Social and Behavioral Sciences, 229, 298-306. https://doi.org/10.1016/j.sbspro.2016.07.140

Hennig-Thurau, T. (2004). Customer orientation of service employees: Its impact on customer satisfaction, commitment, and retention. International Journal of Service Industry Management, 15(5), 460-478. https://doi.org/10.1108/09564230410564939

Herhausen, D. (2011). Understanding proactive customer orientation: construct development and managerial implications. Springer Science \& Business Media.

Hurley, R. F., \& Hult, G. T. M. (1998). Innovation, market orientation, and organizational learning: an integration and empirical examination. The Journal of Marketing, 42-54. https://doi.org/10.2307/1251742

Idar, R., Youssef, Y., \& Mohammed, R. (2012). The effect of market orientation as mediator to strategic planning practices and performance relationship: evidence from Malaysian SMEs. Procedia Economics and Finance, 4, 68-75. https://doi.org/10.1016/S22125671(12)00322-X

Jaworski, B. J., \& Kohli, A. K. (1993). Market orientation: antecedents and consequences. The Journal of Marketing, 53-70. https://doi.org/10.2307/1251854

Jiang, R., \& Kortmann, S. (2014). On the importance of mediating dynamic capabilities for ambidextrous organizations. Procedia CIRP, 20, 85-92. https://doi.org/10.1016/j.procir. 2014.05.036

Jones, E., Buschb, P., \& Dacinc, P. (2003). Firm market orientation and salesperson customer orientation: interpersonal and intrapersonal influences on customer service and retention 
in business-to-business buyer-seller relationships. Journal of Business Research, 56(4), 323-340. https://doi.org/10.1016/S0148-2963(02)00444-7

Kirca, A. (2011). The effects of market orientation on subsidiary performance: Empirical evidence from MNCs in Turkey. Journal of World Business, 46(4), 447-454, Middle East Special Issue Section. https://doi.org/10.1016/j.jwb.2010.10.005

Kohli, A. K., \& Jaworski, B. J. (1990). Market orientation: the construct, research propositions, and managerial implications. The Journal of Marketing, 1-18. https://doi.org/10.2307/1251866

Lai, C. S., Pai, D. C., Yang, C. F., \& Lin, H. J. (2009). The effects of market orientation on relationship learning and relationship performance in industrial marketing: The dyadic perspectives. Industrial Marketing Management, 38(2), 166-172. https://doi.org/10.1016/ j.indmarman.2008.12.004

Mariadoss, B. J., Chi, T., Tansuhaj, P., \& Pomirleanu, N. (2016). Influences of firm orientations on sustainable supply chain management. Journal of Business Research, 69(9), 3406-3414. https://doi.org/10.1016/j.jbusres.2016.02.003

Naidoo, V. (2010). Firm survival through a crisis: The influence of market orientation, marketing innovation and business strategy. Industrial Marketing Management, 39(8), 1311-1320. https://doi.org/10.1016/j.indmarman.2010.02.005

Narver, J. C., \& Slater, S. F., 1990. The effect of a market orientation on business profitability. The Journal of Marketing, 20-35. https://doi.org/10.2307/1251757

Ndubisi, N. O. (2011). Conflict handling, trust and commitment in outsourcing relationship: A Chinese and Indian study. Industrial Marketing Management, 40(1), 109-117. https://doi.org/10.1016/j.indmarman.2010.09.015

Newman, A., Prajogo, D., \& Atherton, A. (2016). The influence of market orientation on innovation strategies. Journal of Service Theory and Practice, 26(1), 72-90. https://doi.org/10.1108/JSTP-02-2015-0044

Özşahin, M., Zehir, C., Acar, A. Z., \& Sudak, M. K., 2013. The effects of leadership and market orientation on organizational commitment. Procedia-Social and Behavioral Sciences, 99, 363-372. https://doi.org/10.1016/j.sbspro.2013.10.504

Pousa, C., \& Mathieu, A., 2014. Boosting customer orientation through coaching: a Canadian study. International Journal of Bank Marketing. 32(1), 60-80. https://doi.org/10.1108/ IJBM-04-2013-0031

Powpaka, P. (2006). How market orientation affects female service employees in Thailand. Journal of Business Research, 59(1), 54-61. https://doi.org/10.1016/j.jbusres.2005.03.004

Rapp, A., Beitelspacher, L. S., Schillewaert, N., \& Baker, T. L. (2012). The differing effects of technology on inside vs. outside sales forces to facilitate enhanced customer orientation and interfunctional coordination. Journal of Business Research, 65(7), 929936. https://doi.org/10.1016/j.jbusres.2011.05.005

Rapp, A., Trainor, K.J., \& Agnihotri, R. (2010). Performance implications of customerlinking capabilities: Examining the complementary role of customer orientation and CRM technology. Journal of Business Research, 63(11), 1229-1236. https://doi.org/10.1016/j.jbusres.2009.11.002

Saboo, A., \& Grewal, R. (2013). Stock market reactions to customer and competitor orientations: the case of initial public offerings. Journal Marketing Science, 32(1), 70-88. https://doi.org/10.1287/mksc.1120.0749

Salahudin, S. N., binti Baharuddin, S. S., Abdullah, M. S., \& Osman, A. (2016). The effect of Islamic work ethics on organizational commitment. Procedia Economics and Finance, 35, 582-590. https://doi.org/10.1016/S2212-5671(16)00071-X 
Šályová, S., Táborecká-Petrovičová, J., Nedelová, G., \& Ďad'o, J. (2015). Effect of marketing orientation on business performance: a study from Slovak foodstuff industry. Procedia Economics and Finance, 34, 622-629. https://doi.org/10.1016/S2212-5671(15)01677-9

Singh, R., \& Koshy, A. (2011). Does salesperson's customer orientation create value in B2B relationships? Empirical evidence from India. Industrial Marketing Management, 40(1), 78-85. https://doi.org/10.1016/j.indmarman.2010.09.012

Slater, S. F., \& Narver, J. C. (1994). Market orientation, customer value, and superior performance. Business Horizons, 37(2), 22-28. https://doi.org/10.1016/0007-6813 (94)90029-9

Suliyanto, S., \& Rahab, R., 2012. The role of market orientation and learning orientation in improving innovativeness and performance of small and medium enterprises. Asian Social Science, 8(1), 134. http://dx.doi.org/10.5539/ass.v8n1p134

Thakor, M. V., \& Joshi, A. W. (2005). Motivating salesperson customer orientation: insights from the job characteristics model. Journal of Business Research, 58(5), 584-592. https://doi.org/10.1016/j.jbusres.2003.10.002

Theoharakis, V., \& Hooley, G., 2008. Customer orientation and innovativeness: Differing roles in New and Old Europe. International Journal of Research in Marketing, 25(1), 69-79. https://doi.org/10.1016/j.ijresmar.2007.09.007

Wei, Z., Zhao, J., \& Zhang, C., (2014). Organizational ambidexterity, market orientation, and firm performance. Journal of Engineering and Technology Management, 33, 134-153. https://doi.org/10.1016/j.jengtecman.2014.06.001

Zhang, D. (2008). Integration of market and entrepreneurial orientation (doctoral dissertation, University of Manitoba).

Zhang, J. A., Edgar, F., Geare, A., \& O'Kane, C. (2016). The interactive effects of entrepreneurial orientation and capability-based HRM on firm performance: The mediating role of innovation ambidexterity. Industrial Marketing Management, 59, 131-143. https://doi.org/10.1016/j.indmarman.2016.02.018

Zhou, K., and Li, C. (2007). How does strategic orientation matter in Chinese firms? Asia Pacific Journal Management, 24, 447-466. https://doi.org/10.1007/s10490-007-9048-1 